\title{
Value of hypotonic duodenography as an adjunct to pancreatic scanning
}

\author{
D. M. McCARThy, L. KREEL, J. E. AGNEW, AND \\ I. A. D. BOUCHIER \\ From the Departments of Medicine, Radiology, and Physics, Royal Free Hospital, \\ London
}

SUMMARY A technique has been developed which allows the position of the upper gastrointestinal tract, as determined radiographically, to be superimposed on the pancreatic photoscan, performed after an injection of ${ }^{75} \mathrm{Se}$-selenomethionine. Results of the technique applied to 27 'abnormal' and 23 'normal' subjects are described. The importance of the additional information gained by the combined technique is discussed in terms of normal variation and increased diagnostic yield, and the situations in which it was found most useful are described. The addition of correlated duodenography rendered scan reporting more objective in $50 \%$ of cases.

Comparisons of the usefulness of radiological and other techniques in solving specific diagnostic problems in pancreatic disease have been undertaken by a number of workers (Sullivan, Meaney, Rodríguez-Antúnez, and Brown, 1966: Kreel, 1967; Eaton, Fleischli, Pollard, Nebesar, and Portsaid, 1968). The reports suggest that all the techniques have well defined 'blind spots'. Pancreatic scanning after injection of ${ }^{75} \mathrm{Se}$-selenomethionine (Rodríguez-Antúnez, Filson, Sullivan, and Brown, 1966; Centi Colella and Pigorini, 1967; Brown, Sircus, Smith, Donaldson, Dymock, Falconer, and Small, 1968; Melmed, Agnew, and Bouchier, 1968) and hypotonic duodenography (Raia and Kreel, 1966; Bilbao, Frische, Dotter, and Rösch, 1967; Kreel, 1969; Martel, 1968) have proved to be simple, safe procedures particularly when 'tubeless' hypotonic duodenography is employed. Our experience is similar to that of Eaton et al (1968) and suggests that these are generally the most useful techniques employed in the diagnosis of pancreatitis and pancreatic carcinoma, though distinction between the two conditions is often difficult.

A technique, described below, has been developed which allows the position of the duodenal loop, as determined by duodenography, to be superimposed on the photoscan. Using this technique a study was undertaken aimed primarily at answering the question, 'Does the addition of correlated hypotonic duodenography as a routine procedure in patients subjected to pancreatic scanning yield additional information helpful to the interpretation of the scan?'
The study also allowed close examination of the scan in difficult interpretive situations. These arise when glandular uptake of the isotope is poor and not greatly in excess of background activity; when the isotope appears in abnormal sites or concentrations; or when the liver or bowel overlaps the pancreas. Under such conditions it may be difficult if not impossible to delineate precise boundaries of the gland. For such reasons one-tenth of scans are unreadable and as many more are interpreted with little confidence. The technique was therefore employed in the hope of reducing this uncertainty and it permitted close study of isotope distribution in the context of known anatomical relations of the pancreas. As no similar studies had been previously reported, interpretation of the results of the study was carried out at a communal reporting session for the first 30 cases, in an effort to detect recurrent patterns. Subsequently scans and duodenograms were reported 'blind' in 20 cases before correlation, in an effort to determine the value of the correlation procedure per se as a source of additional information.

\section{METHODS}

Fed patients, whose drugs had been discontinued 48 hours before scanning, were injected with ${ }^{75}$ Se-selenomethionine within one hour of eating and transferred to the Physics Department where pancreatic and hepatic scans were performed in succession. The patients were then transferred to the Department of Radiology where tubeless duodenographic studies were carried out. 
High residue foods and excessive fats were avoided in the diet in order to minimize gastric retention.

SCANNING An intravenous injection of ${ }^{75}$ Se-selenomethionine was given in a dosage of $3 \mu \mathrm{Ci}$ per kilogram body weight about 40 minutes before scanning. Scans were performed on supine patients using a Picker MagnaScanner ${ }^{1}$ with a 5 in. $\times 2$ in. sodium iodide crystal, an 85-hole collimator of nominal focal length of 5 in., and a standard scanning speed of $24 \mathrm{~cm} /$ second, using a pulse height analyser setting of 210 to $310 \mathrm{KeV}$. The machine gives a photoscan and colour-coded printout (scintigram) for each run and allows the position of external reference markers to be typed on to these prints at the time of scanning. No special preparations, drugs, diets, shields, or scanning positions were used. Liver size and position were then determined by scanning and related to the same external reference markers. For this purpose ${ }^{198} \mathrm{Au}-$ colloidal gold was used. Because of the relatively short half-life, a standard dose of $150 \mu \mathrm{Ci}$ was given intravenously and scans were carried out 10 minutes later at a speed of $60 \mathrm{~cm} / \mathrm{seconds}$. External radioopaque markers were attached to the skin at the top of the costal angle and along the lower margins of the rib cage at standard points. The lines formed by these points were then transferred to the scintiscan by means of the printer, as was the position of the umbilicus.

RADIOLOGY Patients were given 70 to $120 \mathrm{ml}$ of neat Micropaque $^{2}$ to drink, and the progress of the barium was observed, using an image-intensifier. When the loop and proximal small bowel had been outlined adequately an intravenous injection of $6 \mathrm{mg}$ oxyphenonium bromide ${ }^{3}$ was given to abolish peristalsis. The duodenal loop was then examined in detail and thereafter, centring the beam over the mid-point of the loop, a single $6 \mathrm{ft}$ radiograph was taken for correlation purposes with the patient supine.

Leaving the patient and film in position, three small consecutive slit beam exposures were made. The first was coronal and centred over the xiphisternal marker, the other two were taken centring on the costal margin marker with the beam in the line of the costal margin. It was thus possible to overcome distortion due to parallax and accurately superimpose the radiograph on the scan image.

A tracing was made from this radiograph of the lower end of the oesophagus, stomach, duodenum, and proximal jejunum in relation to the position of the radioopaque markers. This tracing, on acetate paper or clear $x$-ray film, was next superimposed on the liver scan and the outlined position of that organ added to the trace. The whole was then superimposed on the pancreatic scan and the aspects of correlation were assessed. For the patient the extra time added to the scanning procedure by hypotonic duodenography was about 20 minutes. In many cases full double-contrast gas-distension duodenography (Raia and Kreel, 1966) was carried out subsequently. In three such studies abnormalities not visible on the plain

${ }^{1}$ Picker, $X$-ray Corp, New York.

${ }^{2}$ Damancy \& Co Ltd

${ }^{3}$ Antrenyl, Ciba Ltd antero-posterior view were discovered but only the latter was employed in evaluating the superimposition technique.

\section{PATIENTS}

Fifty patients were studied by the combined technique. All of the patients had an estimation of serum amylase, a glucose tolerance test, and a plain film of the abdomen for calcification. In 25 of them information about the state of the pancreas was obtained at laparotomy. Additional studies which were undertaken included cholangiograms in 12, Lundh tests in eight, and pancreatic angiography in two patients. All the patients were followed up for a minimum of six months and $50 \%$ of them for a year. Classification of the state of the pancreas from all the information available, other than the scanning or duodenographic procedures, was undertaken at the end of this time. All but two patients were unequivocally classified 'normal' or 'abnormal'. For the purpose of the investigation the two equivocal cases were regarded as 'normal', and on this basis studies had been performed on 27 'abnormal' patients and 23 'normal' patients.

\section{RESULTS}

CORRELATION BETWEEN THE POSITION OF THE HEAD OF THE PANCREAS AS PREDICTED FROM THE SCAN AND FROM DUODENOGRAPHY The radiographs could not be used to predict the position of the neck, body, or tail of the pancreas and observations were therefore confined to the head. In no patient was there an exact correlation between the two predictions in the 50 cases studied. In half of the studies there was fairly close correlation, in that maximal isotopic uptake was in the middle of the loop, but no accurate linear boundaries could be determined. In Fig. 1 the normal anatomy of the duodenum is shown, the numbers on the inner margin indicating the conventional anatomical parts. The only portion of the duodenum which could be consistently related to the head of the pancreas was the second part, there being great variation in the position of the first, third, and fourth parts.

For the purpose of description we have arbitrarily divided the second part of the duodenum into thirds, $\mathrm{AB}, \mathrm{BC}, \mathrm{CD}$, as shown in Fig. 1, the segments AB, $A C$, and $A D$ corresponding to one-third, twothirds, and the whole of the second part respectively. The frequency with which increasing lengths of the inner margin of the duodenal loop (the 'radiographic head') corresponded closely with the periphery of the area of isotope uptake (the "isotopic head') is shown in Table $I$.

In many normal and abnormal scans a double outline of head activity could be seen consisting of a dense central area due to the isotope within the head and a less dense peripheral area due to activity in the adjacent bowel. An example of this effect 


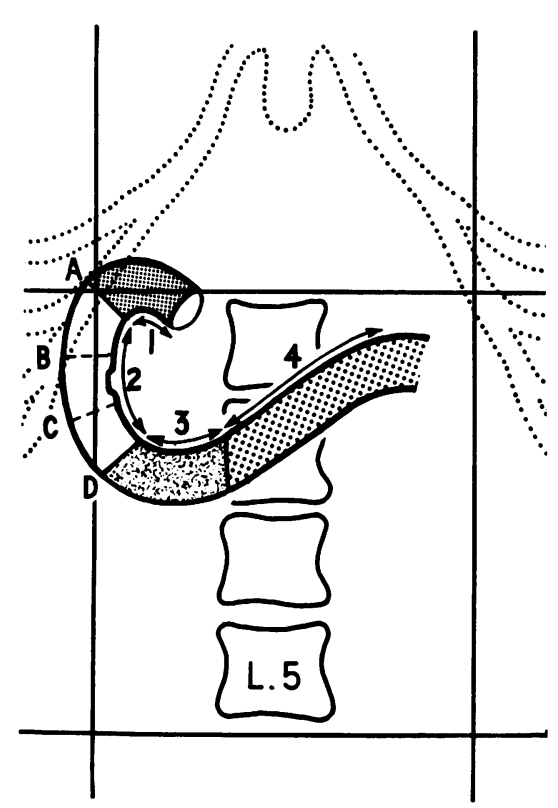

FIG. 1. Normal anatomy of duodenum. The relatively constant second part has been described in terms of the segments $A B, A C$, and $A D$.

TABLE I

FREQUENCY OF CORRELATION OVER INCREASING LENGTHS OF SECOND STAGE OF DUODENUM

\begin{tabular}{lll} 
Segment & \multicolumn{2}{l}{$\begin{array}{l}\text { Correspondence of 'Radiographic' and } \\
\text { 'Isotopic' Head (\%) }\end{array}$} \\
\cline { 2 - 3 } & All Patients (50) & Normals (23) \\
\hline AB (1/3) & 64 & 70 \\
AC (2/3) & 50 & 52 \\
AD (2nd part) & 34 & 39 \\
No correspondence & & 30 \\
in any segment & 36 &
\end{tabular}

in the typical study of a 'normal' subject is shown in Figure 2. Here the bowel trace abuts on the periphery of the head, as indicated by the scan. However, this relationship is inconstant in the group as a whole and occurred no more frequently than the converse, $i e$, the presence of a slight gap between the two structures without overlap. In abnormal cases with low isotopic uptake in the head it became more difficult to separate activity in the head from that believed to be in the adjacent bowel. An example of this type of diagnostic problem, showing the value of the correlation in assessing the contribution of the bowel, is shown in Fig. 3, and the example is discussed more fully below.

The size of the duodenal loop did not vary predictably with the size of the head, measured isotopically, in normal or abnormal subjects. Even restricting conclusions to patients who had correspondence over the areas $\mathrm{AC}$ or $\mathrm{AD}$, the size of the 'isotopic head' was either larger or smaller than the size of the 'radiographic' head in roughly equal numbers. The greatest discrepancy arose through variation in the distal second and third parts of the duodenum and frequently suggested 'enlargement of the duodenal loop'. This appearance was more commonly associated with hepatomegaly, or old age ( $>70 \mathrm{yr}$ ), than with the presence of pancreatic disease.

The position of the pancreas itself seemed relatively constant and never appeared displaced downwards. However, in a number of cases where there was marked hepatomegaly the whole duodenum appeared to lie caudal to the pancreas. An example of this total failure of correspondence is shown in Figure 4.

The duodenum appeared displaced to the left, overlying the 'isotopic head', in a number of cases of chronic pancreatitis, as in Figure 5.

While the existence of a slight gap between the 'isotopic head' and the medial margin of the loop was common, a marked enlargement of this gap was observed in six cases of chronic or relapsing pancreatitis. This might indicate the presence of nonfunctioning areas in an enlarged head, as the medial margin of loop was indented at these levels, despite the presence of the gap. An example is shown in Figure 6.

Body weight, height, width of costal angle, and area which required scanning (temporal length of scan) could not be shown to have any effect on the correlation study nor did the presence of duodenal ulceration (five cases), duodenal diverticula (three cases), or pyloroplasty (three cases). In contrast, patients aged over 70 (five cases), vagotomy (four cases), gastroenterostomy (two cases), or significantly impaired glucose tolerance (three cases) were all associated with diminution of isotopic uptake to a point where it was difficult to delineate precise boundaries of the head. In these people knowledge of the position of the bowel was very helpful in interpreting the scan, especially in deciding that a particular patch of uptake could not have been in the bowel and was therefore in the head. The normality or otherwise of uptake of the head could then be assessed.

The degree of hepatomegaly, confirmed isotopically, and the degree of 'overlap' of the pancreas by the liver on the ${ }^{75} \mathrm{Se}$-selenomethionine scan were separately graded using an arbitrary system and corresponded closely in $75 \%$ of cases. In $25 \%$, however, there was considerable hepatomegaly without an overlap problem. Again accurate knowledge of the position of the bowel was helpful to the 


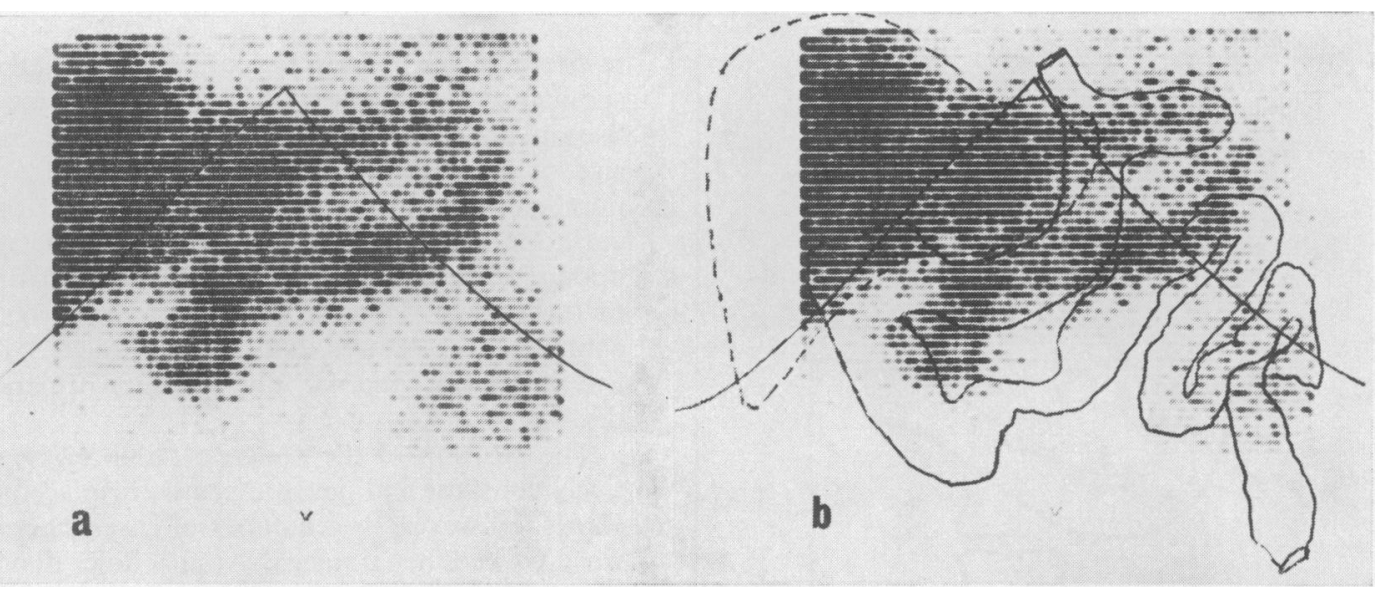

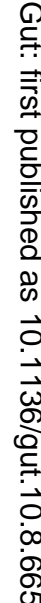

FIG. 2. Typical correlation study in a normal subject. (a) ${ }^{75}$ Se-selenomethionine scan and (b) correlation of the scan with the radiographic study. This format is followed in the subsequent examples.

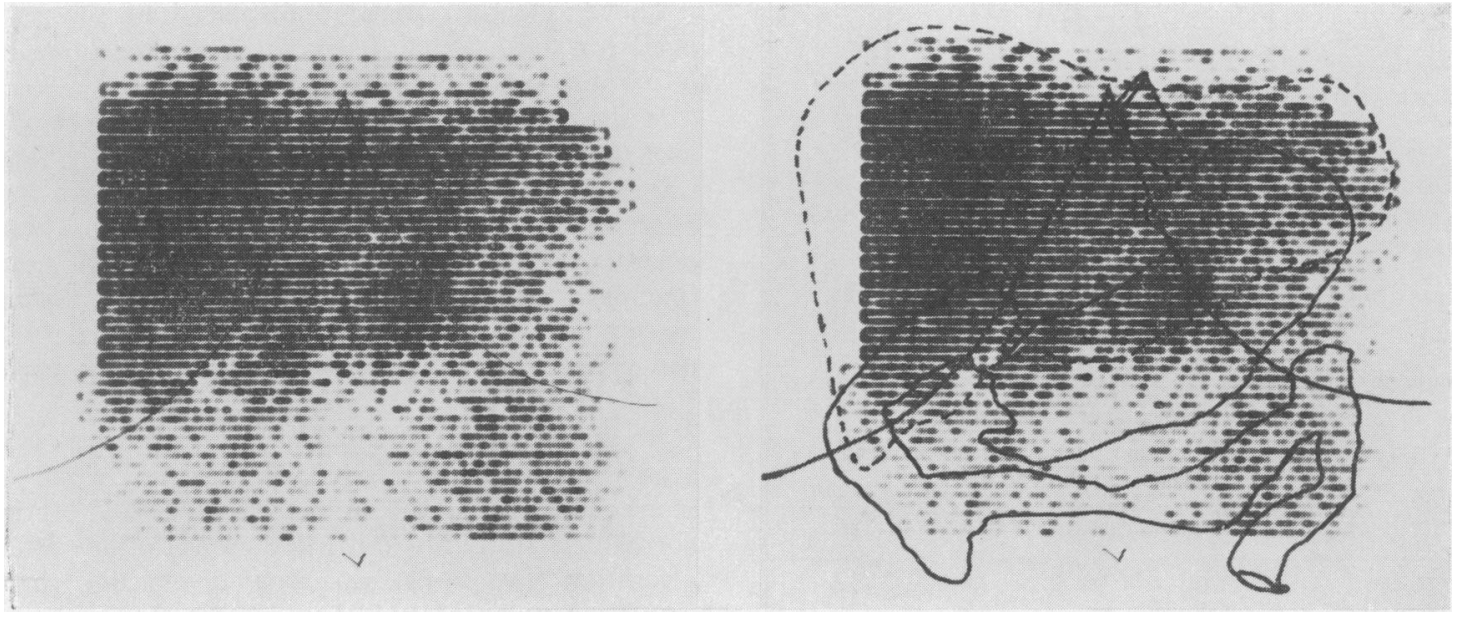

FIG. 3. Study in an abnormal subject. The lower right-hand margin of the head is not definable nor is the contribution to activity from isotope in bowel easily assessed. With correlation an abnormality of the head can be predicted.
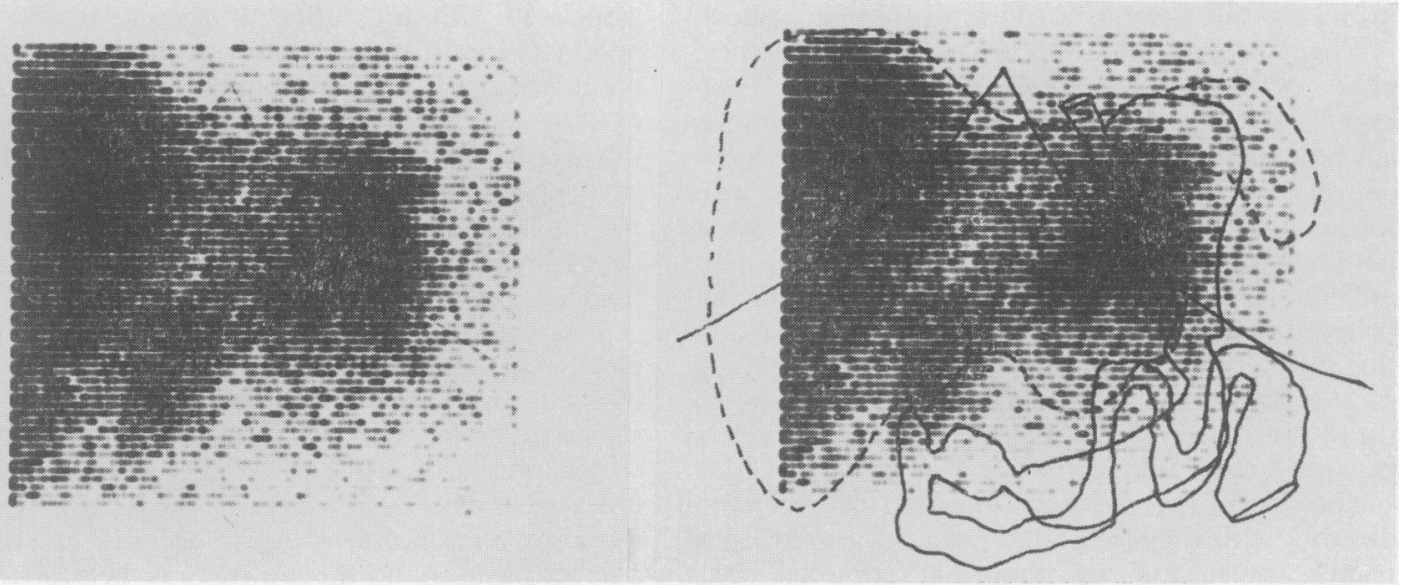

FIG. 4. Total failure of correspondence of 'isotopic' and 'radiographic' heads, associated with hepatomegaly. 


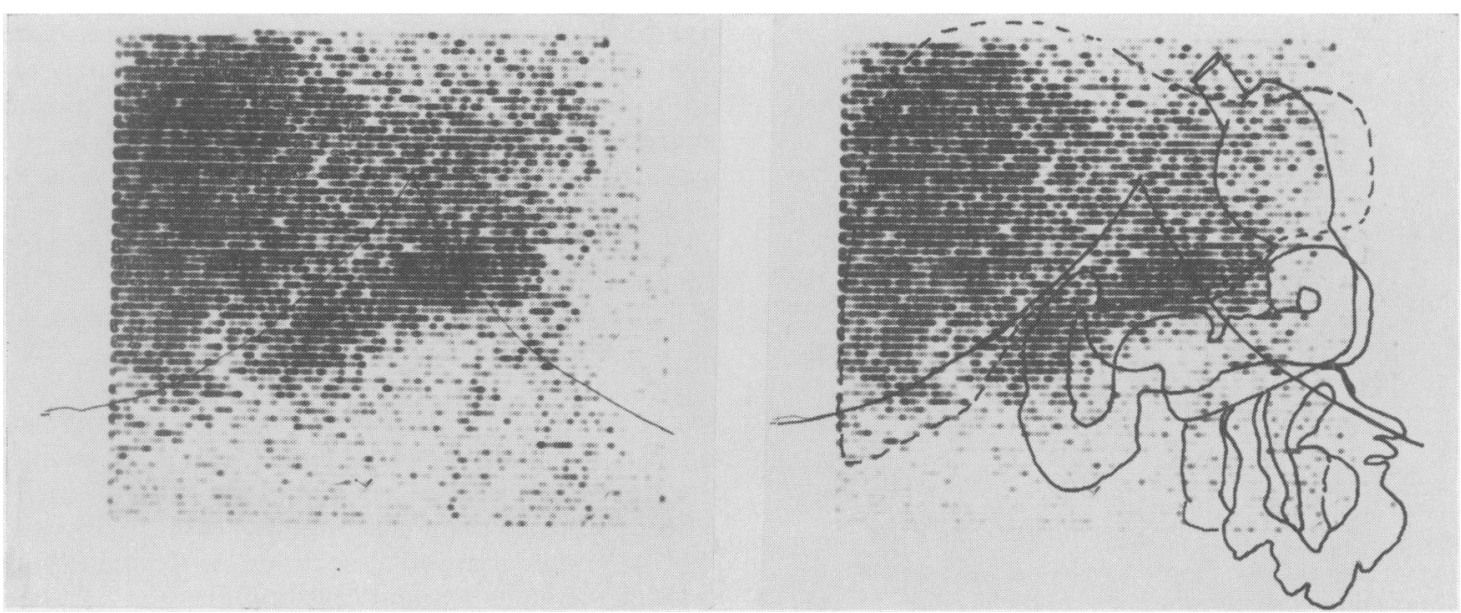

FIG. 5. The duodenum appears displaced to the left, and isotopic activity extends to the right, beyond the limits of the duodenum.

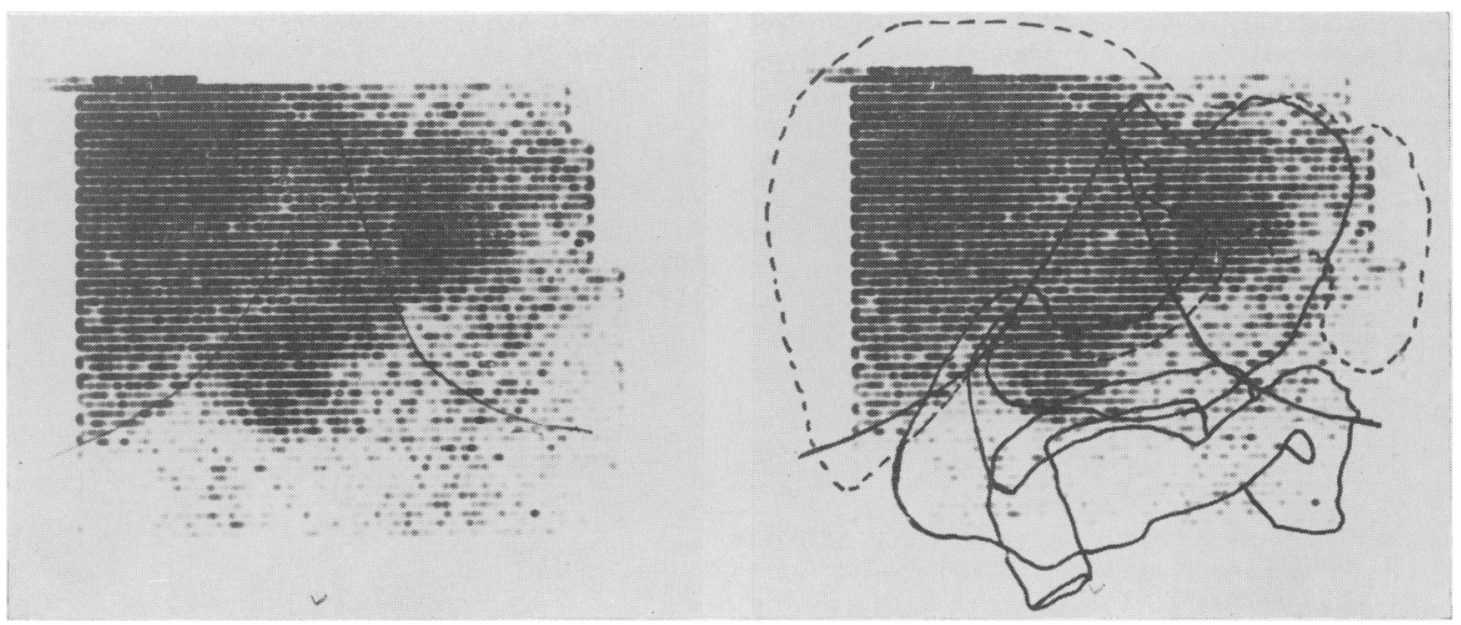

FIG. 6. While the medial margin of the distal second part of the duodenum was stretched and indented radiologically, there was no isotopic uptake noted in the area of radiographic abnormality.

analysis of reinforcement patterns, particularly in determining the position of the head of an overlapped pancreas.

EXAMINATION OF ISOTOPIC EMISSION FROM AREAS CORRESPONDING TO THE BOWEL The differentiation of activity in the bowel from activity in the pancreas is difficult for areas of bowel immediately adjacent to or overlying the gland.

The position of the duodenojejunal flexure was relatively constant, though the site of the nearby pancreatic tail varied considerably as shown in Figure 7. The direction taken by the proximal jejunum, distal to the flexure, was also found to vary considerably. In six out of 50 cases it crossed medially and to the right, overlying the gland and consequently reinforcing 'pancreatic activity' in this area. This probably resulted in failure to diagnose poor glandular uptake of isotope in several abnormal cases and occurs to some extent in the example shown in Figure 6. In addition the first loop of the jejunum often crossed the midline to a point to the right of the head of the pancreas and slightly below it, and occasionally was associated with elevated count rates in that area. The width and shape of the duodenum also varied considerably and isotope in it also gave rise to activity below and to the right of the head.

While considerable variation was noted in count rates recorded over 'background', bowel, and normal 


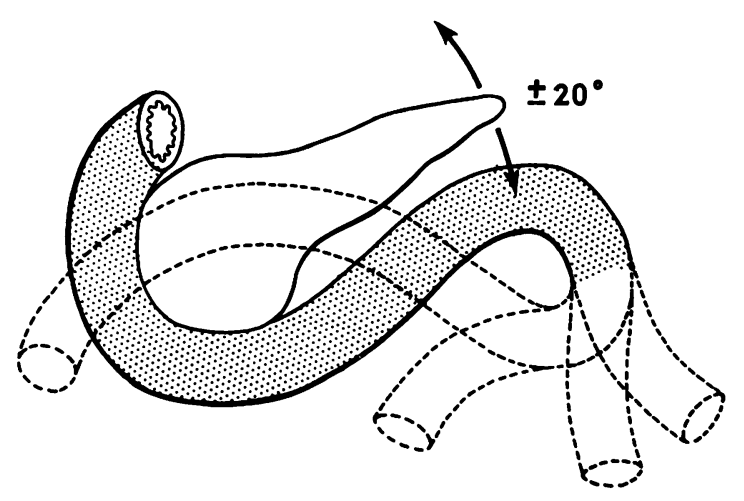

FIG. 7. Variations in position of the tail of the pancreas and of the nearby loop of proximal jejunum. Emissions from these structures reinforce each other to varying degrees.

pancreatic areas the rates of emission recorded over the bowel were usually intermediate between those recorded over the other two areas. Quantitatively significantly elevated counts were recorded over one or more areas of the bowel immediately adjacent to the pancreas in every case. The percentages of the 50 cases with increased activity over each of four arbitrarily selected areas of duodenum are shown in Table II. In general the highest counts were recorded in the 'periampullary' and 'duodenojejunal' areas, and increased activity was also most common in these two areas in all the cases studied.

TABLE II

FREQUENCY OF OCCURRENCE OF SIGNIFICANT ACTIVITY OVER VARIOUS PARTS OF THE DUODENUM

Part of Duodenum

Cases Showing Activity (\%)

\begin{tabular}{ll}
\hline Second & 66 \\
Third & 40 \\
Fourth & 40 \\
Duodenojejunal flexure & 88
\end{tabular}

The importance of emission from bowel is illustrated in Fig. 3, which shows an abnormal scan that is difficult to interpret. The pancreas is overlapped by the left lobe of the liver in the region of the body and tail, but reinforcement of the hepatic emission in this area suggests the presence of functioning pancreatic tissue of questionable normality. The scan gives no information as to the size or site of the head. The appearance could be due to a small totally overlapped normal pancreas, or to diminished uptake in the head of the gland, to a point where it could not be distinguished from other sources of emission. However in superimposing the trace, the probable contribution by bowel to radioactivity in various areas can be assessed. Note the large gap between the edge of the strongly reinforced area on the photoscan and the medial margin of the loop. In this area, predicted as the position of the head, uptake well in excess of background but less than normal is noted in an area devoid of bowel. The scan can then be reported as showing 'very poor activity in the head'. This patient had relapsing pancreatitis due to a stone at the lower end of the pancreatic duct.

USEFULNESS OF THE DIAGNOSTIC MEASURES INDIVIDUALLY Evaluating the procedures individually against the final diagnosis, the techniques were about equally effective in detecting abnormality of the pancreas, but no better than $60 \%$ accurate in distinguishing between pancreatitis and carcinoma.

In discovering 'abnormals', irrespective of the kind of abnormality, the successes of the two techniques are given in Table III. One or both tests were abnormal in 26 out of 27 'abnormal' patients. In four cases duodenography revealed something that the scanning technique had missed, in two cases scanning revealed an abnormality missed on duodenography, and three 'normal' patients with equivocal abnormalities on duodenography were confidently regarded as 'normal' after good, normal photoscans.

\section{TABLE III}

COMPARATIVE VALUE OF DUODENOGRAPHY AND SCANNING IN DETECTING PANCREATIC ABNORMALITY

\begin{tabular}{|c|c|c|c|c|}
\hline \multirow[t]{2}{*}{ Conclusion } & \multicolumn{2}{|l|}{ Scan } & \multicolumn{2}{|c|}{ Duodenography } \\
\hline & $\begin{array}{l}\text { Blind } \\
\text { Series } \\
(20)\end{array}$ & $\begin{array}{l}\text { Overall } \\
\text { Series } \\
(50)\end{array}$ & $\begin{array}{l}\text { Blind } \\
\text { Series } \\
(20)\end{array}$ & $\begin{array}{l}\text { Overall } \\
(50)\end{array}$ \\
\hline $\begin{array}{l}\text { Abnormal in } \\
\text { 'abnormal' cases }(\%)\end{array}$ & 90 & 85 & 90 & 74 \\
\hline $\begin{array}{l}\text { Normal in } \\
\text { 'abnormal' patients }(\%) \\
\text { (false negative) }\end{array}$ & 10 & 15 & 10 & 26 \\
\hline $\begin{array}{l}\text { Abnormal in } \\
\text { normal patients }(\%) \\
\text { (false positive) }\end{array}$ & 5 & 16 & 15 & 14 \\
\hline
\end{tabular}

The scans of eight 'normal' patients were reported blind as abnormal but enquiry revealed that all eight patients were either vagotomized (five) or suffering from severe familial diabetes (three), and no false conclusions were drawn from the scans, though reporting was less confident. Three 'abnormal' patients who had normal scans were recovering from recent acute pancreatitis. The scan of one 'abnormal' patient who had a carcinoma of the head of the pancreas was reported normal. This abnormality was 
also missed on duodenography and on combined study.

DIAGNOSTIC USEFULNESS OF THE CORRELATED STUDY The value of the correlation procedure was classified in three ways, irrespective of whether or not the patient was finally regarded as 'normal' or 'abnormal'. After an initial report on the scan on its own, the trace was then superimposed on it and the correlated study was judged as follows.

Essential The correlated study provided information which materially altered the initial interpretation of the scan. This information was most often useful in determining the exact nature of an abnormality rather than in deciding between abnormal and normal scans, but in a few cases resulted in an equivocal scan or duodenogram being classified as 'normal'.

Useful The correlated study yielded additional information helpful to the assessment, without qualitatively changing the basic conclusion of the initial report or adding any new conclusions, irrespective of benefit from one or both tests without correlation.

Of no value The correlated study provided no additional information.

In the final 20 cases (11 abnormal, nine normal), after 'blind' reporting of the scan and duodenogram individually, the correlation by means of the super- imposition technique was judged 'essential' in five cases $(25 \%)$, 'useful' in a further four $(20 \%)$, and 'of no value' in $11(55 \%)$.

In the light of concepts developed during the study, the initial 30 cases were re-evaluated at the end of the period as objectively as possible and in the overall series of 50 cases ( 27 'abnormal', 23 'normal') the combined study was deemed 'essential' in seven cases $(14 \%)$, 'useful' in a further $17(34 \%)$, and 'of no value' in $26(52 \%)$. The technique was quite useful when there were ambiguous reports from either method alone.

An example of the sort of study in which the combination was judged 'essential' is shown in Figure 8. This scan was reported blindly. 'There is an enlarged liver overlapping the pancreas which is of questionable normality; some activity is noted at area A, clearly separate from the overlapped area, which could be originating in the bowel or possibly in the pancreatic head but this cannot be interpreted with certainty'. The duodenography was 'normal'. Using the superimposition technique it was seen that there was no bowel in area A so that the activity seen there probably originated in the head. Hence the uptake of isotope within the head was very poor, and judging from the pattern of reinforcement in the overlapped area, poorer than in the gland as a whole. The head size, site, and shape were irregular and the head probably enlarged. Taking these findings in the

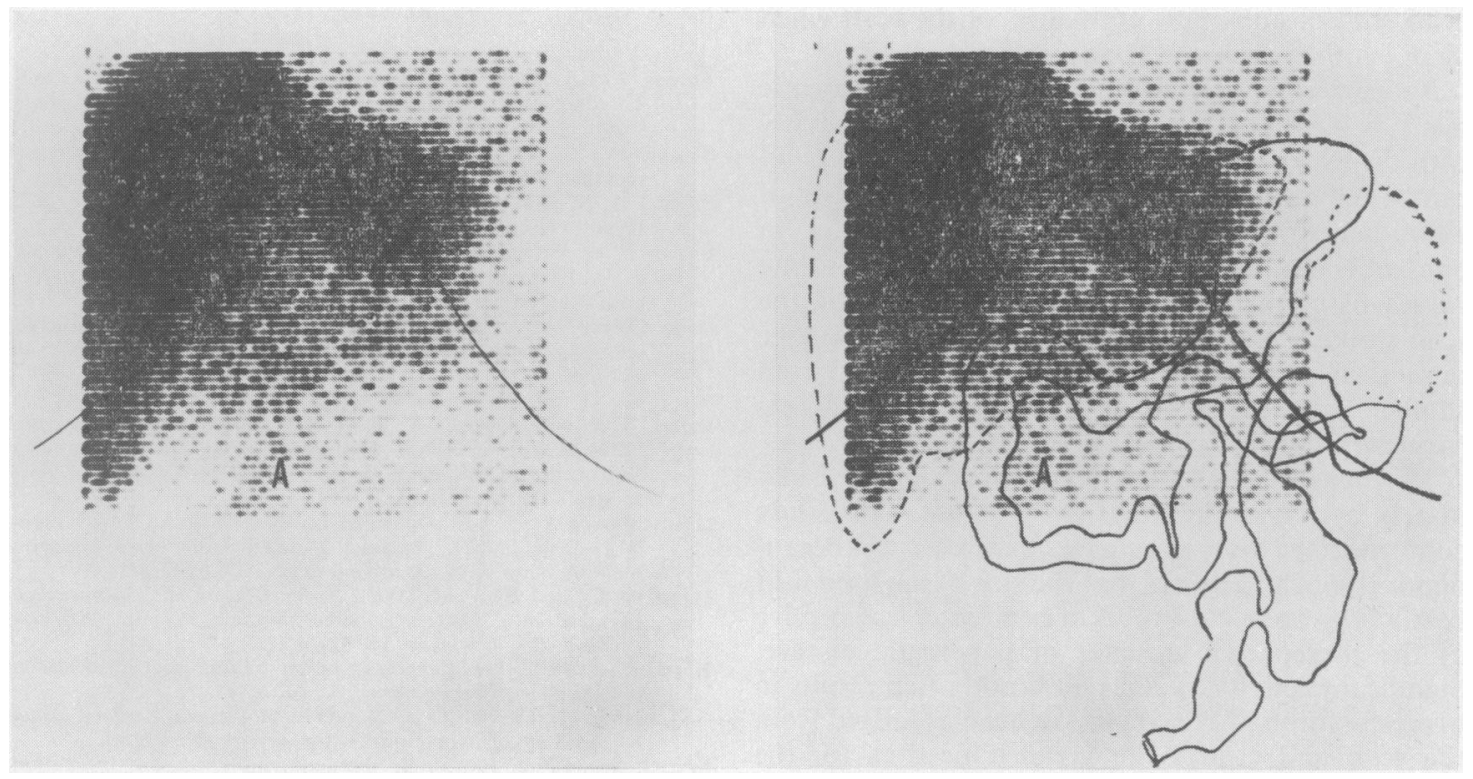

FIG. 8. The technique establishes that the activity at area $A$ is in the head rather than in the bowel and the activity of the head is thus clearly reduced. 
context of hepatomegaly (extrahepatic block) a diagnosis of probable carcinoma of the head was made. This was confirmed at laparotomy.

An example of a 'useful' but not essential study is the example in Fig. 3, where before the duodenography we strongly suspected the presence of pancreatitis but which was reported on the scan with little certainty.

\section{DISCUSSION}

Photoscans of the pancreas give direct information about pancreatic morphology and function (Brown et al, 1968) but edge differentiation is poor and the technique is most likely to fail when the periphery of the gland is abnormal. Radiographic techniques yield only indirect information on pancreatic morphology and are of least use when the periphery of the gland is normally shaped and situated, irrespective of pathology in other parts. Hopes of finding a simple linear correspondence between the 'isotopic head' and 'radiographic head' on using the superimposition technique faded early in the study but it can be seen from the results that much useful information was obtained in certain groups. External markers may be applied before scanning in all cases and the patient subsequently sent for radiographic study if the scan shows significant overlap by liver, poor isotopic uptake in the gland, patches of radioactivity in inappropriate areas, filling defects in the head, and/or apparent 'normality' of the scan when there is other evidence of pancreatic disease.

As currently practised, reporting on pancreatic scans is largely subjective, and results vary greatly with the experience of the reporter. This subjectivity can be reduced in about half the cases by the use of additional radiographic data. This modification in our hands was of more value than analysis of absolute values of count rates from different areas of the scan studied relative to values in other areas of the same scan, or relative to mean values obtained from similar areas in normal and abnormal subjects (Agnew, McCarthy, and Bouchier, 1969).

The size of the head can be assessed only approximately by any method currently in use. This study confirmed the view previously expressed by Beranbaum (1966) and others that the size of the loop is at best a very poor indication of head size, irrespective of the presence or absence of pancreatic disease. Significant activity in adjacent bowel often results in overestimation of the size of the head as judged from the scan and clearly the greatest need is for the development of an isotopically labelled compound which will have a higher specific affinity for the pancreas.
The physiological significance of activity recorded over loops of bowel is probably complex. Presence of the isotope has been recorded in pancreatic juice (Hansson and Blau, 1963), bile (Goidsenhoven, Denk, Pfleger, and Knight, 1967), gastric mucosa (Centi Colella and Pigorini, 1968), and has also been noted in material aspirated from the stomach during the present study. Whatever the mechanism involved allowance must be made for the presence of the isotope in extraglandular sites, particularly when reporting on abnormal scans. Presence of isotope in the area of the duodenojejunal flexure may either reinforce the emission pattern of the tail of the gland or give rise to the artefact of a 'horseshoe pancreas'. Correlation of thescan and duodenogram is generally unnecessary if the scan is 'normal', because a normal scan argues strongly against the presence of pancreatic disease (Sodee, 1966; Melmed et al, 1968). On the other hand the additional work involved in carrying out the full study is comparatively small and correlated duodenography should be performed whenever interpretation of the scan is uncertain.

We should like to thank the staffs of the Departments of Radiology and Physics of the Royal Free Hospital for valuable assistance, the physicians and surgeons of that hospital who permitted us to study their patients, and Dr F. Avery-Jones, Dr T. D. Kellog, and Dr Pamela Brown of the Central Middlesex Hospital who referred a number of patients for study.

\section{REFERENCES}

Agnew, J. E., McCarthy, D. M., and Bouchier, I. A. D. (1969). The diagnostic usefulness of count rate analysis in pancreatic scanning. Brit. J. Radiol. In press.

Beranbaum, S. L. (1966). Carcinoma of the pancreas. A bi-directional roentgen approach. Amer. J. Roentgenol., 96, 447-467

Bilbao, M. K., Frische, L. H., Dotter, C. T., and Rösch, J. (1967). Hypotonic duodenography. Radiology, 89, 438-443.

Brown, P. W., Sircus, W., Smith, A. N., Donaldson, A. A., Dymock, I. W., Falconer, C. W. A., and Small, W. P. (1968). Scintillography in the diagnosis of pancreatic disease. Lancet, 1, 160-163.

Centi Colella, A., and Pigorini, F. (1967). Experiences in pancreas scanning using ${ }^{75}$ Se-selenomethionine. Brit. J. Radiol., 40, 662-669.

,-- (1968). Pancreas scanning. Ibid, 41, 74-75.

Eaton, S. B., Fleischli, D. J., Pollard, J. J., Nebesar, R. A., and Portsaid, M. S. (1968). Comparison of current radiological approaches to the diagnosis of pancreatic disease. New Engl. J. Med., 279, 8, 389-396.

Goidsenhoven, G. E. van, Denk, A. F., Pfleger, B. A., and Knight, W. A., Jr (1967). Pancreatic metabolism of $\mathrm{Se}^{76}$ selenomethionine in dogs. Gastroenterology, 53, 3, 403-411.

Hansson, E., and Blau, M. (1963). Incorporation of ${ }^{75}$ Se-selenomethionine into pancreatic juice proteins in vivo. Biochem. Biophys. Res. Commun., 13, 71-74.

Kreel, L. (1967). The pancreas: newer radiological methods of investigation. Postgrad. med. J., 43, 14-23.

(1969). Duodenography. Chapter in Abdominal Surgery, edited by R. Maingot. Appleton-Century-Crofts, New York.

Martel, W. (1968). Hypotonic duodenography without intubation. Radiology, 91, 387.

Melmed, R. N., Agnew, J. E., and Bouchier, I. A. D. (1968). The normal and abnormal pancreatic scan. Quart. J. Med., New Series. 37, 607-624. 
Raia, S., and Kreel, L. (1966). Gas-distension, double-contrast duodenography using the Scott-Harden gastroduodenal tube. Gut, 7, 420-424.

Rodríguez-Antúnez, A., Filson, E. J., Sullivan, B. H., Jr., and Brown, C. H. (1966). Photoscanning in diagnosis of carcinoma of the pancreas. Ann. intern. Med., 65, 730-737.
Sodee, D. B. (1966). Pancreatic scanning. Radiology, 87, 641-645. Sullivan, B. H., Meaney, T. F., Rodríguez-Antúnez, A., and Brown, C. H. (1966). Diagnosis of carcinoma of the pancreas by selective coeliac arteriography and ${ }^{75} \mathrm{Se}$-photoscanning. In Recent Advances in Gastroenterology. Vol. 4, pp. 382-384. Nankodo Co, Tokyo.

\section{The July 1969 Issue}

\section{THE JULY 1969 ISSUE CONTAINS THE FOLLOWING PAPERS}

\section{Signposts}

Peptide-secreting tumours with special reference to the pancreas WILFRED SIRCUS

Persistent haemolysis after infectious hepatitis MARCEL E. CONRAD

Effect of corticosteroids on mouse hepatitis virus infection D. V. DATTA and M. J. ISSELBACHER

Clinical significance of white bile in the biliary tree R. G. EMSLIE, M. E. C. THORPE, J. V. L. COLMAN, C. R. BOUGHTON, G. R. PRITCHARD, and R. J. HOY

Motility studies in diverticular disease of the colon T. G. PARKS and A. M. CONNELL

Part I Basal activity and response to food assessed by open-ended tube and miniature balloon techniques

Part II Effect of colonic and rectal distension

A relation between gastroduodenal muscle contractions and gastric emptying H. S. WEISBRODT, J. N. WILEY, B. F. OVERHOLT, and PAUL BASS

Oesophageal stricture associated with Crohn's disease N. H. DYER, P. L. COOK, and R. A. KEMP HARPER

Absorption of electrolytes from the colon in cases of ulcerative colitis and in control subjects D. GOOPTU, S. C. TRUELOVE, and G. T. WARNER

Definition of megacolon in colitis J. HYWEL JONES and M. CHAPMAN

Faecal flora of patients with ulcerative colitis during treatment with salicylazosulphapyridine E. MARY COOKE
Duodenal $p \mathrm{H}$ values in normal controls and in patients with duodenal ulcer s. J. RUNE and $\mathrm{K}$. VISKUM

The prognosis of the perforated acute duodenal ulcer PAUl CASSELL

Degradation of bile salts by human intestinal bacteria VIVIENNE ARIES, J. S. CROWTHER, B. S. DRASAR, and M. J. HILL

Value of histochemical reactions for muco-substances in the diagnosis of certain pathological conditions of the colon and rectum $M$. ISABEL FILIPE

Hypertrophy of the appendices epiploicae and liponatus polyposis of the colon VALENTINE A. J. SWAIN, WINIFRED F. YOUNG, and ELIZABETH K. PRINGLE

Comparison of three isotopic methods for the study of calcium absorption J. E. AGNEW, A. K. KEHAYOGLOU, and C. D. HOLDSWORTH

\section{Techniques}

Gastric aspiration R. M. HECTOR

A convenient method for inserting small feeding tubes JOHN D. BULLOCK

\section{Comment}

An evaluation of perfusion techniques in the study of water and electrolyte absorption in man G. E. SLADEN and A. M. DAWSON

Notes and activities

Copies are still available and may be obtained from the PUBLISHING MANAGER, BRITISH MEDICAL ASSOCIATION, TAVISTOCK SQUARE W.C.1. price 17s. 6D. 